\title{
BUSINESS CYCLES, GROWTH, AND IMPORTED ENERGY IN A SMALL-OPEN GROWTH MODEL
}

\author{
Wei-Bin Zhang \\ Ritsumeikan Asia Pacific University, Japan \\ wbz1@apu.ac.jp
}

\begin{abstract}
This paper generalizes an economic growth model proposed by Zhang (2017) by allowing all constant coefficients to be time-dependent. This paper shows existence of business cycles in the generalized model due to periodic shocks. Zhang's original model is developed for a small open economy with imported energy and imported goods. The economy is composed of two sectors and all markets are perfectly competitive. The economy has fixed land and population. Production side is the same as in neoclassical growth theory, while demand side is modelling with Zhang's utility and concept of disposable income. We generalize and simulate the model. We demonstrate existence of business cycles due to different exogenous periodic shocks.
\end{abstract}

Keywords: business cycles; price of energy, price of imported goods, land distribution; propensity to save; small open economy

JEL clasification: F43; L83

\section{Introduction}

Energy is vital for economic development. Some economies are richly endowed with energies, while some economies have little energies. Typical examples of poor energy and fast economic growth in contemporary economies are Japan, Hong Kong, and Singapore. These economies are consumer of energies. It is thus important to address relationship between consumption of energy and economic development. This study examines a question which a few theoretical economic models address. It is dynamic progress of a small open economy which is dependent on importing energies from global economies. By small economies we mean that they have no strong impact on international markets, for instance, with regard to interest rate, energy price, and some foreign goods.

Our attention is focused on energy as it is an important part of some small economies, such as Hong Kong and Singapore. Moreover, it is well known that the energy crises in the 1970s and recent years had strong effects on the economic structure and growth of some small economies. There are many studies on how global prices of input factors may affect economic growth (e.g., Sachs, 1982; Svensson and Razin, 1983; Matsuyama, 1987; Ghalayini, 2011). As different sectors and households need energy, a change in the price of energy in global market may affect the energy-poor national economy in different ways (Kim and Loungani, 1992; Backus and Crucini, 2000). In order to comprehensively study possible effects of the price of energy on national economic development and economic structure, it is necessary to deal with the issues within a dynamic general equilibrium framework. This study studies the price of energy and economic growth on basis of Uzawa's two-sector growth model in context of a small-open economy. This study analyses how global prices of energies and imported goods affect transitory processes and long-term economic development within neoclassical growth framework for a small-open economy. We focus on identifying existence of business cycles due to periodic exogenous shocks. The study is also a contribution to the literature of business cycles and economic growth. Although there are many studies on business cycles, there are 
only a few theoretical economic models with energies and imported goods for small-open economies (e.g., Zhang 1991, 2005, 2006; Lorenz 1993; Chiarella and Flaschel 2000; Shone 2002; Gandolfo 2005; Puu 2011; Stachurski, et al. 2014).

The model is developed within neoclassical growth theory for a small-open economy. Modern neoclassical growth theory was developed by Solow (1956). Since Solow's seminal work, there are different extensions and generalizations of the Solow model. One of important extensions was developed by Uzawa model. Uzawa $(1961,1963)$ generalized Solow's one-sector growth model to tow-sector economy. This extension makes it possible to study economic structures. There are many models for extending and generalizing the Uzawa two-sector model. They deal with issues related to, for instance, fictions and adaption speeds in various markets, money and inflation, externalities, knowledge, and human capital (e.g., Takayama, 1985; Galor, 1992; Drugeon and Venditti, 2001; Herrendorf and Valentinyi, 2006; Li and Lin, 2008; and Stockman, 2009). This study models domestic production on the basis of neoclassical growth theory with multiple sectors for small-open economies. In fact, there is a large number of the literature on dynamics of small-open economies in neoclassical growth theory (e.g., Obstfeld and Rogoff, 1996; Lane, 2001; Kollmann, 2001, 2002; Benigno and Benigno, 2003; Galí and Monacelli, 2005; Uya, et al. 2013; and Ilzetzki, et al. 2013). Our model is influenced by this literature, especially by a model by Schubert and Turnovsky (2011). The Schubert-Turnovsky model is a small-open growth economic model with imported energy (oil). We apply a different Utility function proposed by Zhang and introduce land and housing (Zhang, 2013).

Another important issue for small economies is that as economies are small, they tend to consume many imported goods. It is important to understand economic mechanisms of consuming foreign, for instance, luxury goods. It is obvious that preferences for imported goods play a significant role in determining consumption of foreign goods. As consumption of foreign goods uses income, economic structure and economic growth may be strongly affected by consuming imported goods. Although the effects of importing foreign goods are often in public debates, economics lacks a proper general equilibrium framework for analyzing the impact on short-run as well as long-run economic growth. The general equilibrium framework by Zhang (2017) deals with these issues in an integrated manner. This paper generalizes an economic growth model proposed by Zhang (2017) by allowing all constant coefficients to be time-dependent. We deal with a small open economy which has no energy and has to import energy from global markets. We organize the study as follows. Section 2 develops generalizes Zhang's model for a small open economy with imported energy by allowing all constant coefficients to be time-dependent. Section 3 shows that the movement of the generalized $\mathrm{m}$ is given by one differential equation. Section 4 confirms existence of business cycles due to exogenous shocks. Section 5 concludes the study. The Appendix checks the results in Section 3.

\section{The model with imported goods and energy}

We now allow the constant coefficients in Zhang's model to be time-dependent. The generalization makes Zhang's model more robust as it is possible to analyze impact of different time-dependent shocks on the economic system. The economy is small and open. It an internationally traded (industrial) good and a non-traded good (services). As in the model of Eicher et al. (2008), the economy also consumes imported good, which is not produced by the national economy. The open economy freely borrows resources from the world or exports goods and lends resources abroad. The price of the industrial good is unity. We use $\delta_{k}(t)$ and $r^{*}(t)$ to represent depreciation rate and interest rate. The rate of interest is determined in global markets. As the economy is small, it is reasonable to assume that price of imported goods $p_{z}(t)$ and price of imported energy $p_{x}(t)$ are exogenously given in global markets. National wealth and 
land are owned by households. Land is fully used for residents and services. All markets are perfectly competitive. No international emigration or/and immigration is allowed.

\section{The industrial sector}

We apply subscript index, $i$ and $s$, to stand for industrial and service sector, respectively. We use $K_{j}(t)$ and $N_{j}(t)$ to denote capital stock and labor force employed by sector $j$, $j=i, s$. Let $X_{j}(t)$ stand for energy used by sector $j$. Production function $F_{i}(t)$ of the industrial sector takes on the following form:

$$
F_{i}(t)=A_{i}(t) K_{i}^{\alpha_{i}(t)}(t) N_{i}^{\beta_{i}(t)}(t) X_{i}^{b_{i}(t)}(t), \alpha_{i}(t), \beta_{i}(t), b_{i}(t)>0, \alpha_{i}(t)+\beta_{i}(t)+b_{i}(t)=1,
$$

where $A_{i}(t), \alpha_{i}(t), \beta_{i}(t)$, and $b_{i}(t)$, are parameters. The wage rate $w(t)$ is determined in domestic labor market. The marginal conditions for industrial sector imply

$$
\begin{aligned}
& r_{\delta}(t)=\alpha_{i}(t) A_{i}(t) k_{i}^{\alpha_{i}(t)-1}(t) x_{i}^{b_{i}(t)}(t), w(t)=\beta_{i}(t) A_{i}(t) k_{i}^{\alpha_{i}(t)}(t) x_{i}^{b_{i}(t)}(t), \\
& p_{x}(t)=b_{i}(t) A_{i}(t) k_{i}^{\alpha_{i}(t)}(t) x_{i}^{b_{i}(t)-1}(t),
\end{aligned}
$$

where

$$
k_{i}(t) \equiv \frac{K_{i}(t)}{N_{i}(t)}, \quad x_{i}(t) \equiv \frac{X_{i}(t)}{N_{i}(t)}, \quad r_{\delta}(t) \equiv r^{*}(t)+\delta_{k}(t) .
$$

From (2) we solve

$$
k_{i}(t)=\left(\frac{b^{b_{i}(t)-1} b_{i}(t) A_{i}(t)}{p_{x}(t)}\right)^{1 / \beta_{i}(t)}, x_{i}(t)=b(t) k_{i}(t), w(t)=\beta_{i}(t) A_{i}(t) k_{i}^{\beta_{i}(t)}(t) x_{i}^{b_{i}(t)}(t),
$$

where

$$
b(t) \equiv \frac{b_{i}(t) r_{\delta}(t)}{\alpha_{i}(t) p_{x}(t)}
$$

\section{The service sector}

We take account of four inputs, capital $K_{s}(t)$, labor force $N_{s}(t)$, energy $X_{s}(t)$, and land $L_{s}(t)$ in service supply. Production function of the service sector $F_{s}(t)$ is

$$
\begin{aligned}
& F_{s}(t)=A_{s} K_{s}^{\alpha_{s}(t)}(t) N_{s}^{\beta_{s}(t)}(t) X_{s}^{b_{s}(t)}(t) L_{s}^{\gamma_{s}(t)}(t), \\
& \alpha_{s}(t), \beta_{s}(t), b_{s}(t), \gamma_{s}(t)>0, \alpha_{s}(t)+\beta_{s}(t)+b_{s}(t)+\gamma_{s}(t)=1,
\end{aligned}
$$


where $A_{s}(t), \alpha_{s}(t), \beta_{s}(t), b_{s}(t)$, and $\gamma_{s}(t)$ are parameters. Let $p(t)$ and $R(t)$ stand respectively for the price of the service and the land rent. The marginal conditions for the service sector are

$$
\begin{aligned}
& r_{\delta}(t)=\alpha_{s}(t) A_{s}(t) p(t) k_{s}^{\alpha_{s}(t)-1}(t) x_{s}^{b_{s}(t)}(t) l_{s}^{\gamma_{s}(t)}(t), \\
& w(t)=\beta_{s}(t) A_{s}(t) p(t) k_{s}^{\alpha_{s}(t)}(t) x_{s}^{b_{s}(t)}(t) l_{s}^{\gamma_{s}(t)}(t), \\
& p_{x}(t)=b_{s}(t) A_{s}(t) p(t) k_{s}^{\alpha_{s}(t)}(t) x_{s}^{b_{s}(t)-1}(t) l_{s}^{\gamma_{s}(t)}(t), \\
& R(t)=\gamma_{s}(t) A_{s}(t) p(t) k_{s}^{\alpha_{s}(t)}(t) x_{s}^{b_{s}(t)}(t) l_{s}^{\gamma_{s}(t)-1}(t),
\end{aligned}
$$

where

$$
k_{s}(t) \equiv \frac{K_{s}(t)}{N_{s}(t)}, \quad x_{s}(t) \equiv \frac{X_{s}(t)}{N_{s}(t)}, l_{s}(t) \equiv \frac{L_{s}(t)}{N_{s}(t)} .
$$

From (5) we get

$$
k_{s}(t)=\frac{\alpha_{s}(t) w(t)}{\beta_{s}(t) r_{\delta}(t)}, \quad x_{s}(t)=\frac{b_{s}(t) r_{\delta}(t)}{\alpha_{s}(t) p_{x}(t)} .
$$

\section{Full employment of input factors}

We use $K(t)$ and $N(t)$ to represent total capital stocks employed by the country and population, respectively. Full employment of labor and capital implies

$$
K_{i}(t)+K_{s}(t)=K(t), \quad N_{i}(t)+N_{s}(t)=N(t) .
$$

We rewrite the above equations as

$$
k_{i}(t) N_{i}(t)+k_{s}(t) N_{s}(t)=K(t), \quad N_{i}(t)+N_{s}(t)=N(t) .
$$

From (7), we solve

$$
N_{i}(t)=\left(K(t)-k_{s}(t) N(t)\right) k_{0}(t), \quad N_{s}(t)=\left(k_{i}(t) N(t)-K(t)\right) k_{0}(t),
$$

where $k_{0}(t) \equiv\left(k_{i}(t)-k_{s}(t)\right)^{-1}$. We require $k_{0}(t) \neq 0$.

\section{Behavior of domestic households}

We use $L(t)$ and $R(t)$ to represent land and land rent, respectively. It is assumed that national land is equally owned by domestic households. Income from land per household is

$$
\bar{r}(t)=\frac{L(t) R(t)}{N(t)} .
$$


Current income is

$$
y(t)=r^{*}(t) \bar{k}(t)+w(t)+\bar{r}(t)
$$

where $r^{*}(t) k(t)$ is interest payment. Disposable income is

$$
\hat{y}(t)=y(t)+\bar{k}(t)
$$

Disposable income is distributed between saving and consumption. The household spends the disposable income on lot size $l(t)$, consumption of services $c_{s}(t)$, industrial goods $c_{i}(t)$, imported goods $c_{Z}(t)$, energy consumption $c_{x}(t)$, and saving $s(t)$. The budget constraint is

$$
R(t) l(t)+p(t) c_{s}(t)+c_{i}(t)+p_{Z}(t) c_{Z}(t)+p_{x}(t) c_{x}(t)+s(t)=\hat{y}(t) .
$$

From (11) we see that the household's disposable income is used for the consumption and saving. The utility $U(t)$ is assumed to be related to $l(t), c_{s}(t), c_{i}(t), c_{x}(t)$ and $s(t)$ as follows

$$
\begin{aligned}
U(t)=\theta(t) l^{\eta_{0}(t)}(t) c_{s}^{\gamma_{0}(t)}(t) c_{i}^{\xi_{0}(t)}(t) c_{Z}^{\zeta_{0}(t)}(t) c_{x}^{\chi_{0}(t)}(t) s^{\lambda_{0}(t)}(t), \\
\eta_{0}(t), \gamma_{0}(t), \xi_{0}(t), \varsigma_{0}(t), \chi_{0}(t), \lambda_{0}(t)>0,
\end{aligned}
$$

in which $\eta_{0}(t), \gamma_{0}(t), \xi_{0}(t), \varsigma_{0}(t), \chi_{0}(t)$, and $\lambda_{0}(t)$ are the household's elasticity of utility with regard to the lot size, services, industrial goods, imported good, energy consumption, and saving. We call $\eta_{0}(t), \gamma_{0}(t), \xi_{0}(t), \varsigma_{0}(t), \chi_{0}(t)$, and $\lambda_{0}(t)$ propensity to consume lot size, to consume services, to consume industrial goods, to consume imported goods, to consume energy, and to hold wealth, respectively. Maximizing $U(t)$ subject to (11) yields

$$
\begin{aligned}
& l(t)=\frac{\eta(t) \hat{y}(t)}{R(t)}, \quad c_{s}(t)=\frac{\gamma(t) \hat{y}(t)}{p(t)}, \quad c_{i}(t)=\xi(t) \hat{y}(t), \quad c_{Z}(t)=\frac{\varsigma(t) \hat{y}(t)}{p_{Z}(t)}, \\
& c_{x}(t)=\frac{\chi(t) \hat{y}(t)}{p_{x}(t)}, \quad s(t)=\lambda(t) \hat{y}(t),
\end{aligned}
$$

where

$$
\begin{aligned}
& \eta(t) \equiv \rho(t) \eta_{0}(t), \quad \gamma(t) \equiv \rho(t) \gamma_{0}(t), \quad \xi(t) \equiv \rho(t) \xi_{0}(t), \quad \varsigma(t) \equiv \rho(t) \varsigma_{0}(t), \quad \chi(t) \equiv \rho(t) \chi_{0}(t), \\
& \lambda(t) \equiv \rho(t) \lambda_{0}(t), \quad \rho(t) \equiv \frac{1}{\eta_{0}(t)+\gamma_{0}(t)+\xi_{0}(t)+\varsigma_{0}(t)+\chi_{0}(t)+\lambda_{0}(t)} .
\end{aligned}
$$

Change in wealth is savings minus dissavings 


$$
\dot{\bar{k}}(t)=s(t)-\bar{k}(t)
$$

Equation (13) tells that the saving minus the dissaving equals the change in wealth.

\section{Full use of land and demand of and supply for services}

The national land is distributed between the residential use and service production

$$
l(t) N+L_{s}(t)=L(t)
$$

The equilibrium condition for services implies

$$
c_{s}(t) N(t)=F_{s}(t) .
$$

The GDP is defined as

$$
Y(t)=F_{i}(t)+p(t) F_{s}(t)+R(t) l(t) N(t) .
$$

\section{Trade balance}

We introduce $\bar{K}(t)=\bar{k}(t) N(t)$, which is total wealth owned by the economy. Balance of trade $E(t)$ is defined as follows:

$$
E(t)=r^{*}(t)(\bar{K}(t)-K(t)) .
$$

We thus built the growth model of a small open economy. The rest of paper examines behavior of the dynamic system.

\section{The Dynamics of the National Economy}

The Appendix shows that the dynamics of economic system is given by a single differential equation. The following lemma is confirmed in the Appendix.

\section{Lemma}

We determine $k_{i}(t), x_{i}(t), k_{s}(t), x_{s}(t)$, and $w(t)$ as functions of $r^{*}(t)$ and $p_{x}(t)$ by (3) and (6). The land rent is given by the following differential equation

$$
\dot{R}(t)=\bar{\Lambda}(R(t), t),
$$

where $\bar{\Lambda}$ is given as a function of $R(t)$ and $t$ in the Appendix. The other variables are determined as functions of $R(t)$ and $t$ as follows: $\bar{k}(t)$ by (A10) $\rightarrow K(t)$ from (A9) $\rightarrow p(t)$ by (A8) $\rightarrow K_{i}(t)$ and $K_{s}(t)$ from (A1) $\rightarrow N_{i}(t)$ and $N_{s}(t)$ with (A1) $\rightarrow X_{i}(t)=x_{i}(t) N_{i}(t)$ $\rightarrow X_{s}(t)=x_{s}(t) N_{s}(t) \rightarrow \hat{y}(t)$ by $(\mathrm{A} 4) \rightarrow l(t), c_{i}(t), c_{s}(t), c_{Z}(t), c_{x}(t), s(t)$ from (12) $\rightarrow L_{s}(t)$ by $(14) \rightarrow F_{i}(t)$ in (1) $\rightarrow F_{s}(t)$ in (4). 
The Lemma means that the motion of economic system can be uniquely determined by the land rent and the other exogenous variables. Once we determine the movement of the land rent, it is straightforward to describe the movement of the whole system. Another issue in trade theory is about how a country's terms of trade can change the economy's growth (e.g., Mendosa, 1995; Kose, 2002; and Turnovsky and Chattopadhyay, 2003). According to Harberger (1950) and Laursen and Metzler (1950), a deterioration in the terms of trade reduces real income, which decreases saving and investment. The current account balance is deteriorated. This is the so-called Harberger-Laursen-Metzler effect. It should be noted that according to Eicher et al. (2008), "Previous authors have specified the borrowing cost to increase with the nation's level of debt. This specification, together with a constant rate of time preference and inelastic labor supply, implies that terms of trade shocks have no dynamic effects. The only response is that consumption fully adjusts instantaneously, with the current account remained unchanged." Our study has similar conclusions. To see this, we show in the appendix that the price can affect the system only through $p_{Z}(t) c_{Z}(t)=\varsigma(t) \hat{y}(t)$. We thus get

$$
\frac{d c_{Z}(t)}{d p_{Z}(t)}=-\frac{c_{Z}(t)}{p_{Z}(t)}
$$

There are other studies which address issues related to the Harberger-Laursen-Metzler effect (e.g., Obstfeld, 1982; Mansoorian, 1993; Ikeda, 2001).

The rest of this section follows Zhang (2017) to simulate a special case of our model when all the parameters are constant as follows:

$$
\begin{aligned}
& r^{*}=0.06, \quad p_{Z}=4, \quad p_{Z}=6, \delta_{k}=0.05, \quad N=10, L=1, A_{i}=1.5, A_{s}=1, \quad \alpha_{i}=0.3, \\
& \beta_{i}=0.6, \alpha_{s}=0.2, \quad \beta_{s}=0.5, \quad b_{s}=0.1, \quad \lambda_{0}=0.6, \quad \xi_{0}=0.15, \quad \gamma_{0}=0.06, \quad \eta_{0}=0.1, \\
& \varsigma_{0}=0.04, \chi_{0}=0.06 .
\end{aligned}
$$

The rate of interest is fixed at 6 per cent. We chose the population 10. The land is fixed at unity. We specify the propensity to save at 0.6 and the propensity to consume the industrial good at 0.15 . The propensity to consume the industrial good is higher than the propensity to consume services, or propensity to consume imported goods, or to consume housing. The specified parameter values are not according to empirical observations. The time-independent variables are determined by international markets as follows

$$
k_{i}=4.47, k_{s}=3.58, w=0.98, x_{i}=0.027, x_{s}=0.009 \text {. }
$$

We choose the initial condition $R(0)=6$. The motion of the dynamic system is plotted in Figure 1. We start the land rent with its value higher than its equilibrium value. The land rent decreases over time. The price of services falls over time. The household does not change the lot size and the service sector employs the same land. The household reduces the consumption levels of the energy, foreign good, good, and services. 

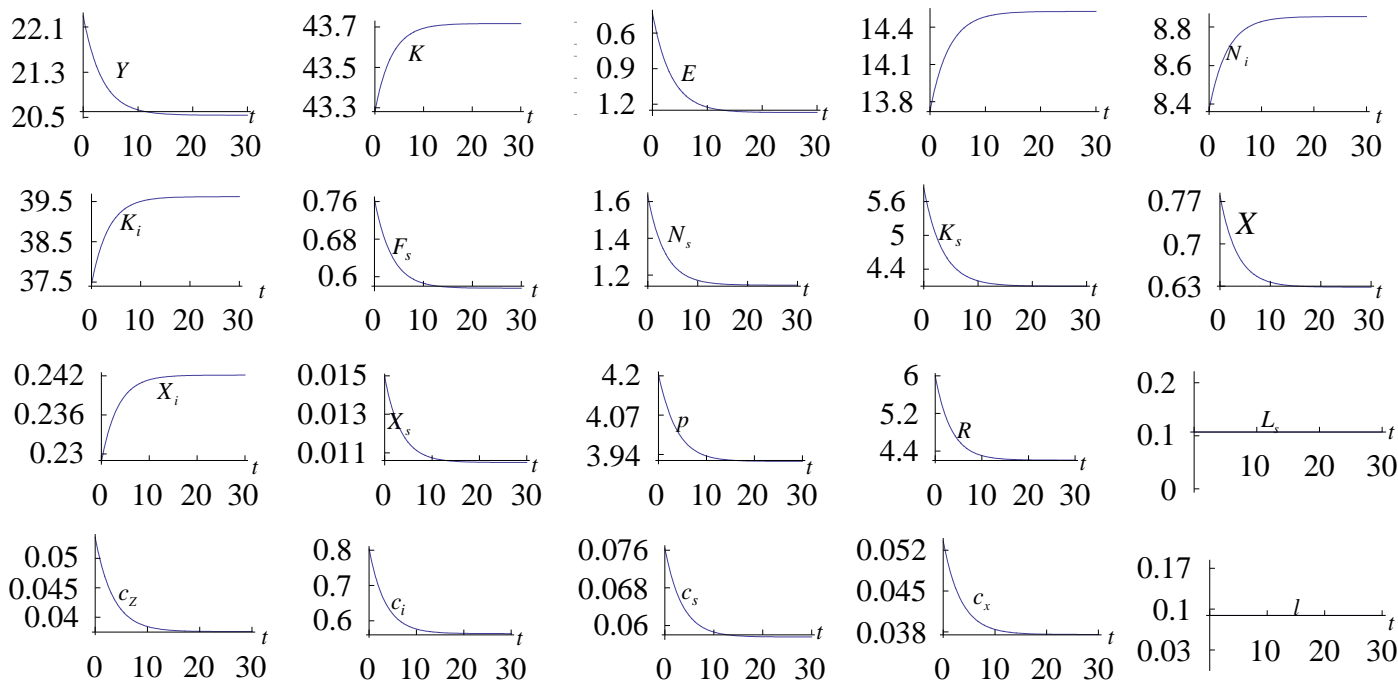

Figure 1 The Motion of the National Economy

Figure 1 shows how the system approaches its equilibrium point. We calculate the equilibrium values of the variables as follows

$$
\begin{aligned}
& p=3.92, \quad R=4.21, Y=20.54, X=0.63, E=-1.27, K=43.72, \bar{K}=22.54, \\
& N_{i}=8.85, \quad N_{s}=1.15, \quad K_{i}=39.62, K_{s}=4.10, \quad X_{i}=0.24, \quad X_{s}=0.10, L_{s}=0.11, \\
& F_{i}=14.53, \quad F_{s}=0.58, \quad c_{i}=0.56, \quad c_{s}=0.06, \quad c_{Z}=0.04, \quad c_{x}=0.04, l=0.09 .
\end{aligned}
$$

The eigenvalue at the equilibrium point is -0.29 . The unique equilibrium point is stable.

\section{Comparative Dynamic Analysis}

The previous section showed the movement of the small-open economy. The simulation results are given in Zhang (2017). We now show existence of business cycles due to periodic exogenous changes. Zhang's original model fails to deal with this kind of issues as it did not allow time-dependent parameter changes. We define a variable, $\bar{\Delta} x(t)$, which represent the change rate of the variable, $x(t)$, in percentage due to changes in value of a parameter.

\subsection{The price of imported energy oscillates periodically}

First, we study a case that the price of imported energy oscillates periodically as follows:

$$
p_{x}(t)=6+0.1 \sin (t)
$$

The simulation result is plotted in Figure 2. It should be noted that there is no change in the land distribution, even though the plots show extremely small change. 

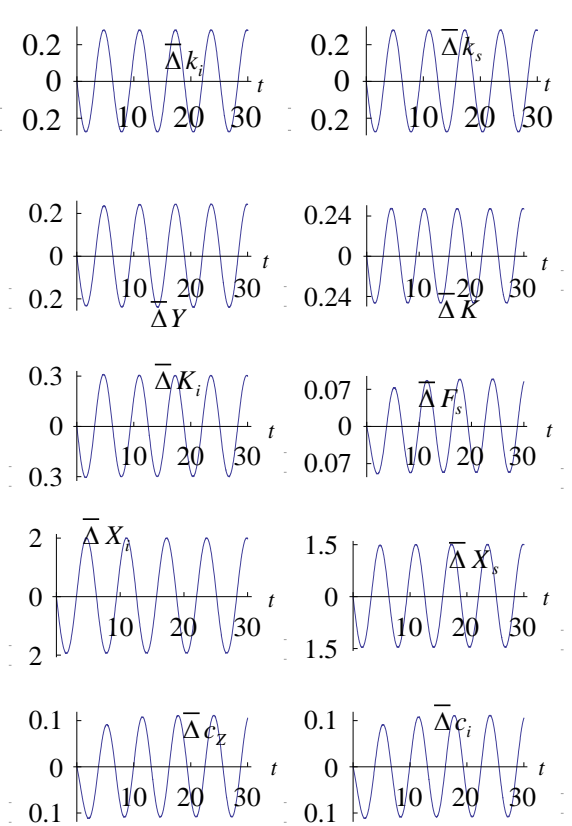
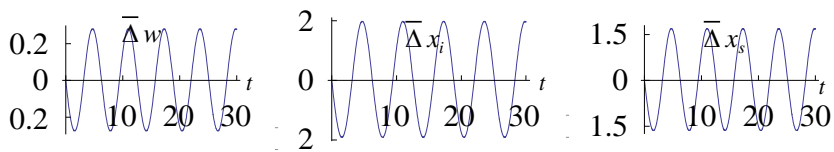
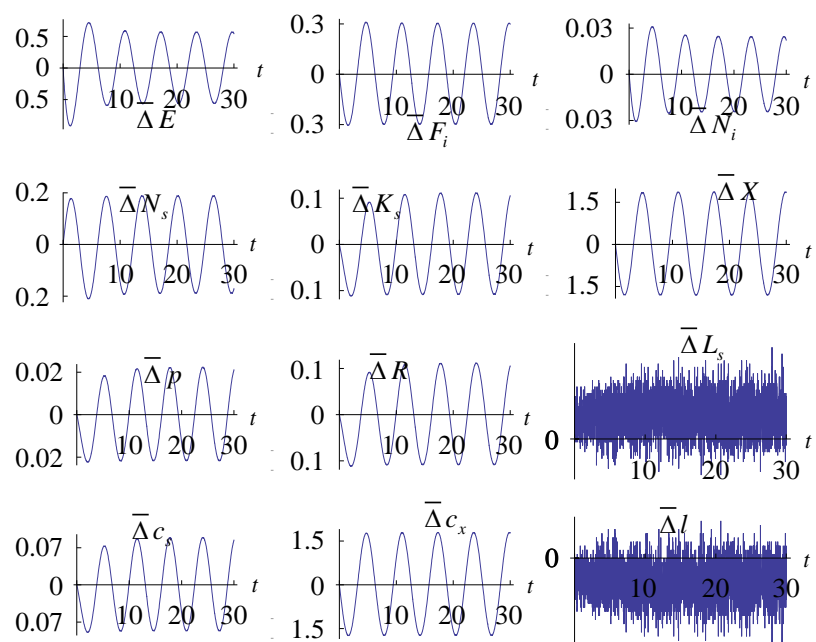

$\bar{\Delta} c_{x}$
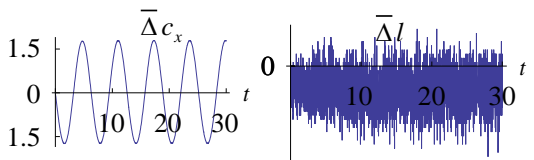

Figure 2. The Price of Imported Energy Oscillates Periodically

\subsection{The propensity to consume imported goods oscillates periodically}

We now allow the propensity to consume imported goods to be changed as follows:

$$
\varsigma_{0}(t)=0.04+0.002 \sin (t)
$$

The changes in the time-dependent variables are plotted in Figure 3. The variables in (19) are not affected. There are business cycles due to the periodic perturbations.
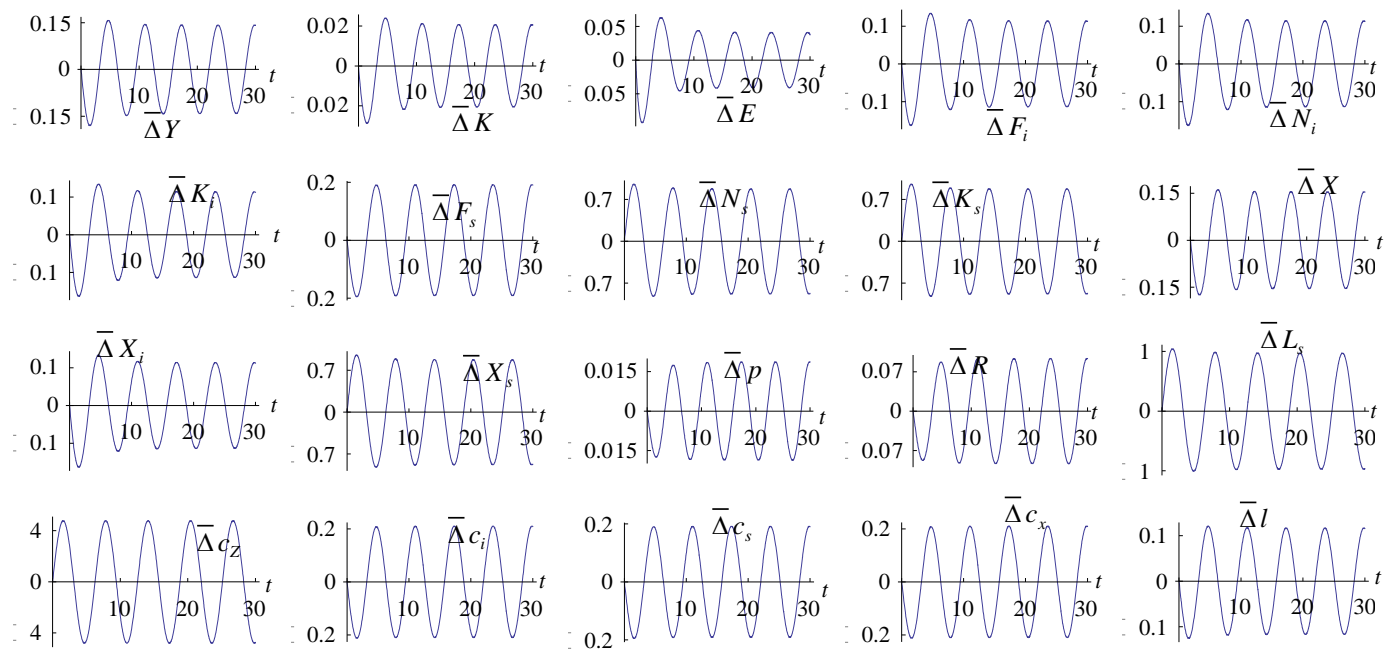

Figure 3. The Propensity to Consume Imported Goods Oscillates Periodically 


\subsection{The rate of interest oscillates periodically}

We now study movement of the economic system when the rate of interest oscillates periodically

$$
r^{*}(t)=0.06+0.002 \sin (t) .
$$

The result is given in Figure 3.

Rise in capital cost reduces the capital intensities, the wage rate and the energy intensities as follows

$$
\Delta k_{i}=\Delta k_{s}=-6.45, \Delta w=\Delta x_{i}=-2.20, \Delta x_{s}=4.55 .
$$

The time-dependent variables are plotted as in Figure 4.
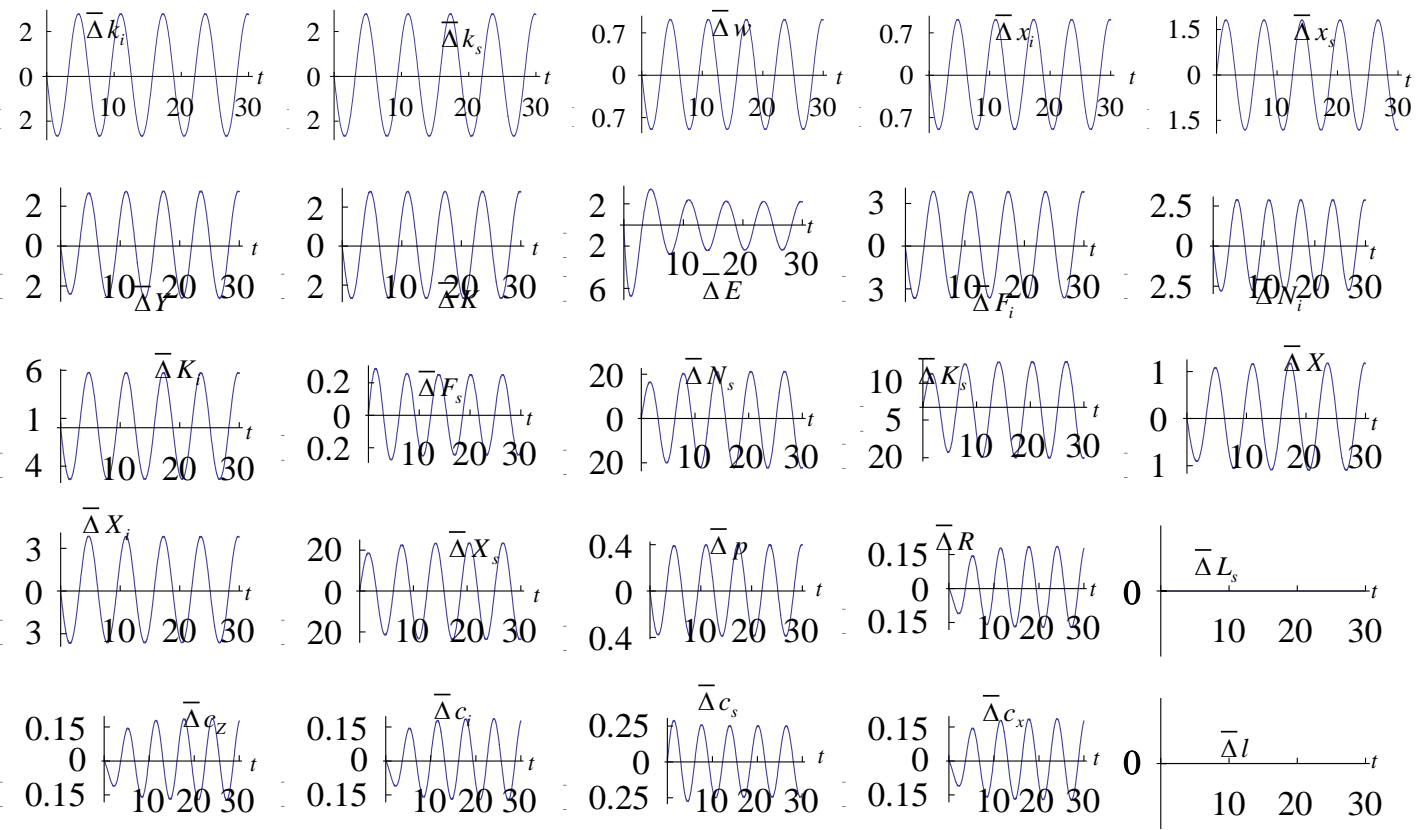

Figure 4. The Rate of Interest Oscillates Periodically

\subsection{The propensity to save oscillates periodically}

We now allow the propensity to save to oscillate periodically as follows:

$$
\lambda_{0}(t)=0.6+0.01 \sin (t)
$$

The changes in the time-dependent variables are plotted in Figure 5. 

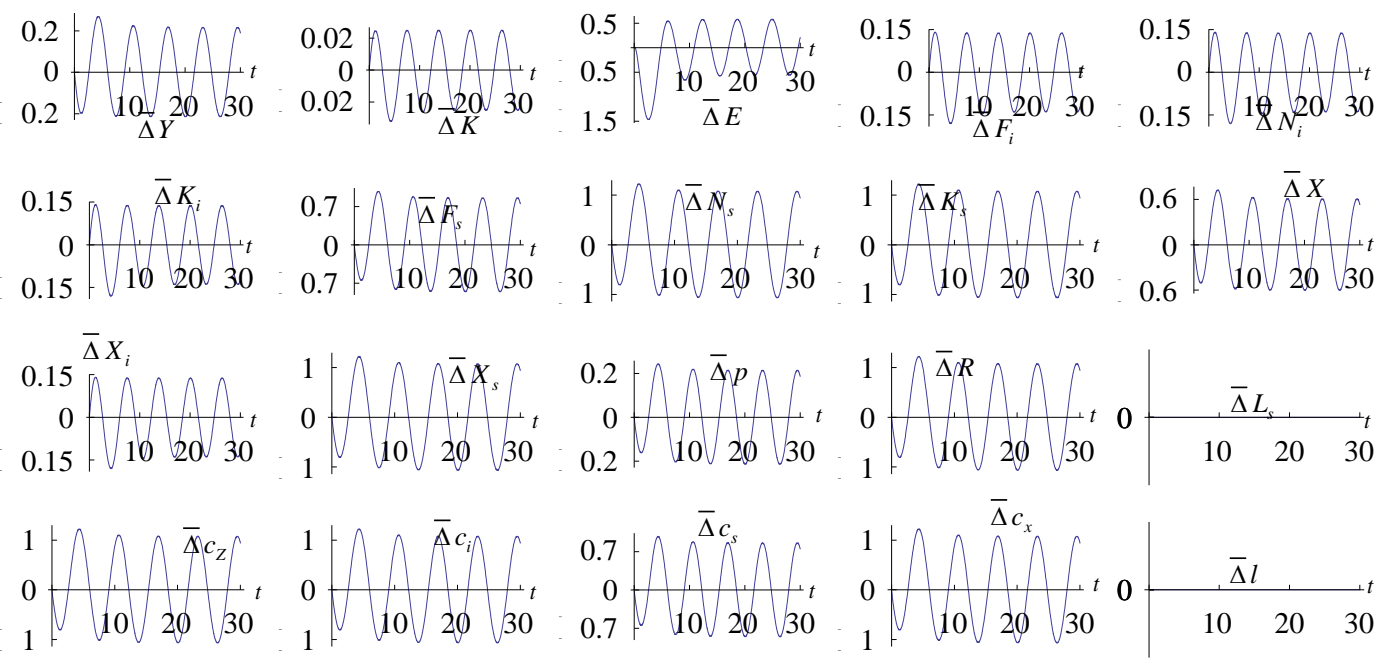

Figure 5. The Propensity to Save Oscillates Periodically

\section{Conclusions}

This paper generalized an economic growth model proposed by Zhang (2017). This paper showed existence of business cycles in the generalized due to periodic shocks. Zhang's original model is developed for a small open economy with imported energy and goods. The economy is perfectly competitive. The production side is the same as in neoclassical growth theory, while demand side is modelling with Zhang's utility and concept of disposable income. We generalized the model and simulated the model. We demonstrated existence of business cycles due to different exogenous shocks. Although it contains some important determinants of economic growth and its structure is already very complicated, the model may be generalized to take account other possibly important determinants of growth, for instance, endogenous human capital and government intervention in trade.

\section{References}

Backus, D.K. and Crucini, M.J. 2000. Oil Prices and the Terms of Trade. Journal of International Economics, 50(1), 185-213.

Benigno, G. and Benigno, P. 2003. Price Stability in Open Economies. Review of Economic Studies, 70(4), 743-64.

Chiarella, C. and Flaschel, P. 2000. The Dynamics of Keynesian Monetary Growth: Macro Foundations. Cambridge University Press, Cambridge.

Eicher, T.S., Schubert, S.F., and Turnovsky, S.J. 2008. Dynamic Effects of Terms of Trade Shocks: The Impact on Debt and Growth. Journal of International Money and Finance, 27(6), 876-96.

Gali, J. and Monacelli, T. 2005. Monetary Policy and Exchange Rate Volatility in a Small Open Economy. Review of Economic Studies, 72(3), 707-34.

Galor, O. 1992. Two-Sector Overlapping-Generations Model: A Global Characterization of the Dynamical System. Econometrica, 60(6) 1351-86.

Gandolfo, G. 2005. Economic Dynamics. Berlin: Springer.

Ghalayini, L. 2011. Interaction between Oil Price and Economic Growth. Review of Middle East Economics and Finance, 13(13), 127-41. 
Harberger, A.C. 1950. Currency Depreciation, Income, and the Balance of Trade. Journal of Political Economy, 58(1), 47-60.

Herrendorf, B. \& Valentinyi, A. 2006. On the Stability of the Two-Sector Neoclassical Growth Model with Externalities. Journal of Economic Dynamics and Control 30(8), 1339-61.

Ikeda, S. 2001. Weakly Non-separable Preferences and the Harberger-Laursen-Metzler Effect. Canadian Journal of Economics 34(1), 290-307.

Ilzetzkia, E., Mendozab, E.G., and Véghc, G.A. 2013. How Big (Small?) Are Fiscal Multipliers? Journal of Monetary Economics, 60 (2), pp. 239-54.

Kim, I. and Loungani, P. 1992. The Role of Energy in Real Business Cycle Models. Journal of Monetary Economics, 29(2), 173-89.

Kose, M.A. 2002. Explaining Business Cycles in Small Open Economies: How Much Do World Prices Matter? Journal of International Economics 56(2), 299-327.

Kollmann, R. 2001. The Exchange Rate in a Dynamic-Optimizing Business Cycle Model with Nominal Rigidities: A Quantitative Investigation. Journal of International Economics, 55(2), 243-62.

Kollmann, R. 2002. Monetary Policy Rules in the Open Economy: Effects on Welfare and Business Cycles. Journal of Monetary Economics, 49(5), 899-1015.

Lane, P.R. 2001. The New Open Economy Macroeconomics: A Survey. Journal of International Economics, 54(2), 235-66.

Laursen, S. and Metzler, L.A. 1950. Flexible Exchange Rates and the Theory of Employment. Review of Economics and Statistics, 32(4), 281-99.

Li, J.L. \& Lin S.L. 2008. Existence and Uniqueness of Steady-State Equilibrium in a Two-Sector Overlapping Generations Model. Journal of Economic Theory, 141(1), 255-75.

Lorenz, H.W. 1993. Nonlinear Dynamic Economics and Chaotic Motion. Springer-Verlag, Berlin.

Mansoorian, A. 1993. Habit Persistence and the Harberger-Laursen-Metzler Effect in an Infinite Horizon Model. Journal of International Economics, 34(1-2), 153-66.

Matsuyama, K. 1987. Current Account Dynamics in a Finite Horizon Model. Journal of International Economics, 23(3-4), 299-313.

Mendosa, E.G. 1995. The Terms of Trade, the Real Exchange Rate, and Economic Fluctuations. International Economic Review, 36(1), 101-37.

Puu, T. 2011. Nonlinear Economic Dynamics. Berlin: Springer.

Obstfeld, M. 1982. Aggregate Spending and the Terms of Trade: Is There a Harberger-Laursen-Metzler Effect? Quarterly Journal of Economics, 97(2), 251-70.

Sachs, J. 1982. The Current Account in the Macroeconomic Adjustment Process. Scandinavian Journal of Economics, 84(2), 147-59.

Schubert, S.F. and Turnovsky, S.J. 2011. The Impact of Oil Prices on an Oil-Importing Developing Economy. Journal of Development Economics, 94(1), 18-29.

Shone, R. 2002. Economic Dynamics - Phase Diagrams and Their Economic Application. Cambridge University Press, Cambridge.

Solow, R. 1956. A Contribution to the Theory of Growth. Quarterly Journal of Economic, 70(1), 65-94.

Stachurski, j., Venditti, A., Yano, M. 2014. Nonlinear Dynamics in Equilibrium Models: Chaos, Cycles and Indeterminacy. Berlin: Springer.

Stockman, D.R. 2009. Chaos and Sector-Specific Externalities. Journal of Economic Dynamics and Control, 33(12), 2030-46.

Svensson, L.E.O. and Razin, A. 1983. The Terms of Trade and the Current Account: The Harberger-Laursen-Metzler Effect. Journal of Political Economy, 91(1), 97-125.

Takayama, A. 1985. Mathematical economics. Cambridge: Cambridge University Press. 
Turnovsky, S.J. and Chattopadhyay, P. (2003) Volatility and Growth in Developing Economies: Some Numerical Results and Empirical Evidence. Journal of International Economics, 59(2), 267-95.

Uya, T., Yi, K.M., and Zhang, J. 2013. Structural Change in an Open Economy. Journal of Monetary Economics, 60(September), pp. 667-82.

Uzawa, H. 1961. On a Two-Sector Model of Economic Growth I. Review of Economic Studies, 29(1), 47-70.

Uzawa, H. 1963. On a Two-Sector Model of Economic Growth II. Review of Economic Studies 30(2), 105-18.

Zhang, W.B. 1991. Synergetic Economics. Heidelberg: Springer-Verlag.

Zhang, W.B. 2005. Differential Equations, Bifurcations, and Chaos in Economics. Singapore: World Scientific.

Zhang, W.B. 2006. Discrete Dynamical Systems, Bifurcations and Chaos in Economics. Elsevier: Amsterdam.

Zhang, W.B. 2013. The Impact of Transport, Land and Fiscal Policy on Housing and Economic Geography in a Small-Open Growth Model. Journal of Transport and Land Use, 6(1), 89-100.

Zhang, W.B. 2017. The Impact of Imported Energy and Goods Prices on Growth and Trade Balances of a Small Open Economy. Bulletin of Economic Theory and Analysis, 2(2), 99-116.

\section{Bio-note:}

Wei-Bin Zhang, PhD (Umeå, Sweden), is Associate Dean of International Cooperation and Research Division, Professor of Economics in Ritsumeikan Asia Pacific University (APU), Japan. His main research fields are nonlinear economic dynamics, growth theory, trade theory, East Asian economic development, and Confucianism. He has published about 240 academic articles (150 in peer-review international journals), authorized 22 academic books in English by international publishing houses. Prof. Zhang is editorial board members of 12 international journals. $\mathrm{He}$ is currently Top Author in Japan in economics in NJP (http://ideas.repec.org/top/top.person.anbpages.html). 


\section{Appendix: Proving the Lemma}

With $K_{j}=k_{j} N_{j}$ and (8), we solve

$$
K_{i}=\left(K-k_{s} N\right) k_{0} k_{i}, \quad K_{s}=\left(k_{i} N-K\right) k_{0} k_{s} .
$$

With (5), $l_{s}=L_{s} / N_{s}$ and $w_{s} \equiv w \gamma_{s} / \beta_{s}$, we obtain

$$
R=\frac{w_{s} N_{s}}{L_{s}} \text {. }
$$

Insert (A2) in (15)

$$
l N+\frac{w_{s} N_{s}}{R}=L \text {. }
$$

From the definition of $\hat{y}$, we have

$$
\hat{y}=\left(1+r^{*}\right) \bar{k}+w+\frac{R L}{N} .
$$

From (A4) and $l=\eta \hat{y} / R$ in (13), we obtain

$$
l=\frac{\left(1+r^{*}\right) \eta \bar{k}+\eta w}{R}+\frac{\eta L}{N} .
$$

Insert this equation in (A3)

$$
\left(1+r^{*}\right) \eta \bar{k}+\eta w+\frac{w_{s} N_{s}}{N}=(1-\eta) \frac{L}{N} R
$$

With $r_{\delta}=\alpha_{s} p F_{s} / K_{s}$ and (15) we solve

$$
c_{s} N=\frac{r_{\delta} K_{s}}{\alpha_{s} p} .
$$

Insert $c_{s}=\gamma \hat{y} / p$ in (A6)

$$
\gamma \hat{y} N=\frac{r_{\delta} K_{s}}{\alpha_{s}} \text {. }
$$

Insert (A4) in this equation

$$
\left(\left(1+r^{*}\right) \bar{k}+w+\frac{R L}{N}\right) \gamma N=\frac{r_{\delta} K_{s}}{\alpha_{s}} .
$$


From (5) and $l_{s}=w_{s} / R$, we get

$$
p=\frac{R^{\gamma_{s}}}{\gamma_{s} A_{s} w_{s}^{\gamma_{s}-1} k_{s}^{\alpha_{s}} x_{s}^{b_{s}}}
$$

Substituting $N_{s}=\left(k_{i} N-K\right) k_{0}$ from (8) into (A5) and $K_{s}=\left(k_{i} N-K\right) k_{0} k_{s}$ from (A1) in (A7), respectively, we get

$$
\begin{aligned}
& \left(1+r^{*}\right) \eta N \bar{k}-w_{s} k_{0} K=\bar{\Psi}, \\
& \left(1+r^{*}\right) \gamma N \bar{k}+\frac{r_{\delta} k_{0} k_{s} K}{\alpha_{s}}=\tilde{\Psi},
\end{aligned}
$$

where

$$
\begin{aligned}
& \bar{\Psi}(R(t))=(1-\eta) L R-\eta w N-w_{s} k_{i} k_{0} N, \\
& \tilde{\Psi}(R(t)) \equiv \frac{k_{i} N r_{\delta} k_{0} k_{s}}{\alpha_{s}}-w \gamma N-R L \gamma .
\end{aligned}
$$

Solve (A9)

$$
\bar{k}=\Psi(R) \equiv \frac{1}{\left(1+r^{*}\right) N}\left(\tilde{\Psi}+\frac{r_{\delta} k_{s} \bar{\Psi}}{\alpha_{s} w_{s}}\right)\left(\gamma+\frac{\eta r_{\delta} k_{s}}{\alpha_{s} w_{s}}\right)^{-1} .
$$

We showed the procedure in the Lemma. From procedure and (13), we get

$$
\dot{\bar{k}}=\Lambda(R, t) \equiv \lambda \hat{y}-\bar{k}
$$

Take derivatives of $(\mathrm{A} 10)$ with respect to time

$$
\dot{\bar{k}}=\frac{\partial \Psi}{\partial R} \dot{R}+\frac{\partial \Psi}{\partial t} \text {. }
$$

From (A11) and (A12), we solve the differential equations for determining the land rent as follows

$$
\dot{R}=\bar{\Lambda}(R, t) \equiv\left(\Lambda-\frac{\partial \Psi}{\partial t}\right)\left(\frac{\partial \Psi}{\partial R}\right)^{-1}
$$

Summarizing the analytical results, we confirmed the Lemma. 